\title{
Predictors of Mortality in Necrotizing Soft Tissue Infections in Adults - Experience at A Tertiary Care Hospital in Pakistan
}

${ }^{1}$ Haroon Javaid Majid, ${ }^{2}$ Muhammad Imran Anwar, ${ }^{3}$ Muhammad Zaeem Khalid, ${ }^{3}$ Shafique-UrRehman, ${ }^{2}$ Muhammad Amir Jameel

${ }^{I}$ Department of General Surgery \& Surgical Oncology, Shaikh Zayed Medical Complex, Lahore

${ }^{2}$ Department of Surgery (Unit-II), Shaikh Zayed Medical Complex, Lahore

${ }^{3}$ Department of Surgery (Unit-I), Shaikh Zayed Medical Complex, Lahore

\begin{abstract}
Introduction: Necrotizing soft tissue infection is a potentially fatal 'flesh-eating' disease that requires prompt intervention to save a patient's life. Identification of parameters that indicate worsening of the disease (predictors of mortality) is an important part in management that guides a surgeon towards rapid surgical treatment.

Aims \& Objectives: This retrospective study aims to identify factors that are associated with mortality in adults with NSTIs. This study also aims to propose solutions for the better management of these infection to improve surgical outcome and survival.

Place and duration of study: OPD \& Emergency of Surgical Unit I and II of Shaikh Zayed Hospital, Lahore over a period of 10 years between the years 2010 to 2021 .

Material \& Methods: This is a cross-sectional epidemiological, retrospective study conducted on patients presenting in the Outpatients Department, as well as the Emergency of Surgical Unit I and II. A total of 72 patients meeting the inclusion criteria were enrolled in this study. SPSS version 23 was used for data analysis.

Results: Out of 72 patients, $31.94 \%$ of patients were receiving some form of immunosuppressive treatment ( $\mathrm{n}=23$ ), out of which 7 patients lost their life $(30.43 \%, \mathrm{p}=0.000)$. There was a preexisting immunosuppressive disease in $48.61 \%$ patients $(n=35)$, and in this subset, a total of 10 patients didn't recover $(28.57 \%, p=0.000) .13$ out of 17 patients who died received first debridement after 12 hours from presentation $(\mathrm{p}=0.021)$. High mortality was seen in patients who had the presence of shock at hospital admission.

Conclusion: Delay in diagnosis and surgical treatment, the presence of shock at admission accompanied by evidence of organ dysfunction, increasing comorbidity index are reasons for the higher mortality seen in these patients of NSTIs. The timing of the first surgery is of the essence thus highlighting the importance of the "Golden Hour" for the Management of NSTIs.
\end{abstract}

Key words: Necrotizing Soft Tissue Infections (NSTIs), Early Diagnosis, Mortality, Debridement

\section{INTRODUCTION}

$\mathbf{N}$ ecrotizing soft tissue infections (NSTI) are rapidly progressive skin and soft tissue infections that cause widespread tissue necrosis and are associated with systemic illness and a high mortality rate and remain a challenge not only for the most experienced surgical team but also require full time involvement at the multidisciplinary level if lives are to be saved. $^{1,2}$ A potentially massively destructive infection, NSTI has popularly been named as a 'flesh-eating disease', which if diagnosed or treated late is associated with a grave outcome. ${ }^{3,13}$ Early diagnosis, adequate resuscitation with simultaneous administration of broad spectrum antibiotics followed by prompt surgical intervention forms the basis of improving the outcome in these critically ill patients. ${ }^{1,2,3,4,5,6}$

NSTIs are variously classified on the basis of the pathogen, the site of the infection and the extent of tissue involvement. ${ }^{4}$ The classification system according to microbiology categorizes, Type 1 which is the commonest and is defined as the presence of multiple microbes, usually involving anaerobes, while on the other hand, Type 2 NSTI have only one documented pathogen, most commonly Group A Streptococcus or less commonly S. Aureus. Clostridia can also be isolated in Type 2 infections. ${ }^{20}$ Type 3 is very rare and caused by Vibrio vulnificans (seawater organism), and Type 4 i.e., Fungal., ${ }^{7,15,16}$ Certain monomicrobial infections include communityassociated MRSA. Different terms can be used to 
describe NSTIs of various anatomic sites, for example necrotizing infection of the perineum is called Fournier's gangrene. Diabetic foot infections are usually polymicrobial and can progress to a necrotizing pattern due to the presence of concomitant microvasculature injury along with the infection. The classically described Meleney's synergistic gangrene is a rare form of necrotizing bacterial infection of the abdominal wall which can develop following abdominal surgery. ${ }^{18}$ If not identified early and treated promptly, it can lead to extensive fatal gangrene. Last but not the least, NSTI are also classified according to the depth of necrosis. 'Necrotizing Cellulitis' is a term used when the infection of the subcutaneous tissue extends into the dermis. 'Necrotizing Fasciitis', as the name suggests, involves the fascia and the term 'Myonecrosis' or 'Necrotizing Myositis' is used when the infection involves the muscles with or without skin manifestations. ${ }^{4}$

Despite better understanding and advances in management, the fatalities from NSTIs have remained constant at around $30 \%$ for the past thirty years or more. ${ }^{4,5,6}$ Thus, we conducted this retrospective study at our institute to identify factors that were significantly associated with mortality in adults with NSTIs.

It is postulated that mortality can be predicted in patients with NSTIs due to the presence of certain indicators on hospital admission and during the course of treatment in one individual setup.

\section{MATERIAL AND METHODS}

This is a cross-sectional, retrospective study done on patients presenting in the Outpatients Department, as well as the Emergency of Surgical Unit I and II of Shaikh Zayed Hospital, Lahore between the years 2010 to 2021 .

Inclusion \& Exclusion Criteria: Adult patients (age $>18$ years) admitted with necrotizing soft tissue infection (NSTI) were included in this study. All patients were ensured for complete records. Both males and females were taken into account.

Four patients who died before surgical intervention could be carried out were excluded from this study because of incomplete records. All patients who had any previous intervention from any setup before presenting at Shaikh Zayed Hospital were also excluded from the study. Type I diabetics were not taken into account as there is a lack of evidence of it causing immunosuppression. Patients with two or more concomitantly affecting variables (for example cancer patients with diabetes) were also not included in this study.

\section{Method}

Patients were identified with and diagnosis was confirmed by a detailed review of medical records. Standard treatment was given to all patients and included early emergency and later scheduled repeated debridement as required, broad-spectrum antibiotic cover, and physiologic and nutritional support followed by early soft tissue reconstruction by the plastic surgery teams. A total of 72 patients who met the inclusion criteria were taken into account and a detailed review of medical records and outcome was analyzed retrospectively for the indicators of fatalities in patients with necrotizing soft tissue infections.

Diabetes and Immunosuppression: Only Type-II diabetics who had diabetes for greater than 10 years were included. Recent studies suggest that long term insulin resistance causes microvascular and macrovascular complications and an abnormal $\mathrm{T}$ cell response causing immunosuppression ${ }^{23}$.

Cancer Induced Immunosuppression: Studies suggest that tumor cells neutralize our host immune response, specifically IL18, hence reducing the ability of our immune system to fight off infections ${ }^{24}$.

Chronic Liver Disease: Chronic Liver Disease is an immunocompromised state that predisposes the patient to infections by gram negative bacteria and is associated with $30 \%$ mortality. This state is characteristically defined as 'Immune Paralysis' that leads to an increase in anti-inflammatory cytokines and a decrease in pro-inflammatory ones. ${ }^{25}$

\section{Statistical analysis:}

The authors used Statistical Package of Social Sciences Version 23 for data analysis and the data compilation and input was carried out by the authors themselves.

\section{RESULTS}

The total number of patients 72 (Males:41, Females:31). Mean Age: 47 years (range $22-71$ years). There was evidence of immunosuppressive treatment in $31.94 \%(n=23)$ of patients, out of which 7 patients lost their life $(30.43 \%, \mathrm{p}=0.000)$. There was a preexisting immunosuppressive disease in $48.61 \%$ patients $(\mathrm{n}=35)$, and in this subset, a total of 10 patients didn't recover $(28.57 \%, \mathrm{p}=0.000)$ while $15.2 \%$ patients had no comorbidities. Table-1 shows details of the predisposing conditions.

Although IM/IV injection sites were the commonest infectious entry pathways, $8 \%$ of the necrotising infections were found to be in post-operative surgical wounds (Table-2). 


\begin{tabular}{|c|c|c|c|}
\hline \begin{tabular}{|c|} 
Patient's Condition at \\
Presentation
\end{tabular} & $\begin{array}{l}\text { Total Number } \\
\text { of Patients }\end{array}$ & Mortality & $\begin{array}{c}\mathrm{P} \\
\text { values }\end{array}$ \\
\hline $\begin{array}{c}\text { Immunosuppressive } \\
\text { treatment }\end{array}$ & 23 & & 0.00 \\
\hline Corticosteroids & 10 & 4 & \\
\hline NSAIDs & 11 & 2 & \\
\hline Chemotherapy & 2 & 1 & \\
\hline $\begin{array}{c}\text { Immunosuppressive } \\
\text { disease }\end{array}$ & 35 & & 0.00 \\
\hline Diabetes Mellitus & 31 & 7 & \\
\hline Cancer & 1 & 1 & \\
\hline Chronic Liver disease & 3 & 2 & \\
\hline PVD & 3 & 0 & - \\
\hline No Comorbids & 11 & 1 & 0.00 \\
\hline
\end{tabular}

Table-1: Pre-Existing conditions

\begin{tabular}{|l|l|}
\hline $\begin{array}{l}\text { Infectious Entry } \\
\text { Pathway }\end{array}$ & $\begin{array}{l}\mathbf{n}=\text { number (\% Percentage). } \\
\text { Total Patients 72 }\end{array}$ \\
\hline Abscess or wound & $\mathrm{n}=27(38 \%)$ \\
\hline Trauma & $\mathrm{n}=6(8 \%)$ \\
\hline Postoperative infection & $\mathrm{n}=6(8 \%)$ \\
\hline IM or IV Injection site & $\mathrm{n}=33(46 \%)$ \\
\hline
\end{tabular}

Table-2: Possible source of infection

Lower limbs were the most affected anatomical site, the trunk/torso was involved in $30.5 \%$ of the patients (Fig-1).

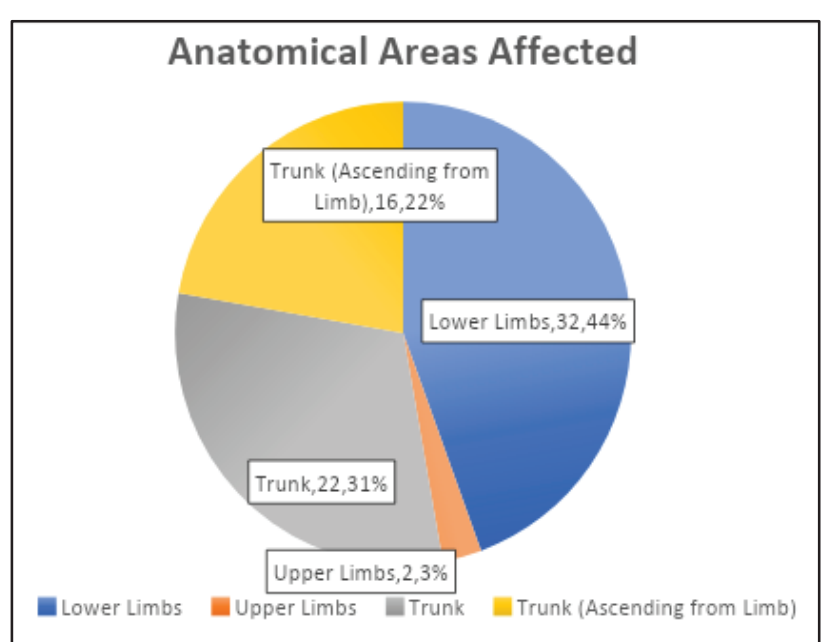

Fig-1: (Percentages of Anatomical sites affected with Necrotizing Soft tissue Infections)

High mortality was seen in patients with primary or secondary involvement of the trunk (11 out of 38 patients, mortality 29\%), NSTI involving postoperative surgical wounds (4 out of 6 patients, mortality $67 \%$ ) and those who had Clostridial NSTI (3 out of 9 patients, mortality 33\%). Any combinations of these criteria were associated with more than $90 \%$ mortality. The 17 patients who died in this group fulfilled at least two or more of these criteria.

The mean time from initial presentation to first surgical intervention was calculated as fourteen hours, ranging from 4 - 42 hours. On average, patients who recovered had a mean of five debridements, ranging from 2 - 10 debridements. Additionally, $23.5 \%$ of the total mortalities were operated before 12 hours from the time of admission while $76.5 \%$ of the total mortalities were operated after 12 hours or beyond. Late diagnosis, delayed presentation and the time from admission to surgical management of more than 12 hours was associated with a higher rate of mortality ( $\mathrm{p}=0.021-$ Table-3).

\begin{tabular}{|c|c|c|}
\hline $\begin{array}{c}\text { Time of Surgical } \\
\text { Intervention After } \\
\text { Presentation }\end{array}$ & $\begin{array}{c}\text { Total Mortalities in } \\
\text { the Subset }\end{array}$ & P value \\
\hline$>12$ hours & 13 & \multirow{2}{*}{0.021} \\
\hline$<12$ hours & 4 & \\
\hline
\end{tabular}

Table 3: Time of first surgical intervention

\begin{tabular}{|c|c|c|}
\hline $\begin{array}{c}\text { Patients who were received in } \\
\text { shock and had the following }\end{array}$ & $\begin{array}{c}\text { Number } \\
\text { of Patients } \\
\text { Received }\end{array}$ & $\begin{array}{c}\text { Total } \\
\text { Mortalities }\end{array}$ \\
\hline $\begin{array}{c}\text { High white cell count } \\
(>25,000 \times 103 / \mu \mathrm{L})\end{array}$ & 5 & 1 \\
\hline $\begin{array}{c}\text { Raised serum Creatinine } \\
(>2 \mathrm{mg} / \mathrm{dL})\end{array}$ & 6 & 1 \\
\hline Heart Disease & 4 & 2 \\
\hline $\begin{array}{c}\text { High White Cell Count and } \\
\text { Raised Serum Creatinine }\end{array}$ & 6 & 4 \\
\hline $\begin{array}{c}\text { High White Cell Count, Raised } \\
\text { Serum Creatinine and Heart } \\
\text { Disease }\end{array}$ & 2 & 1 \\
\hline Total & 23 & 9 \\
\hline
\end{tabular}

Table-4: Patients received in shock

Four patients had to undergo amputations (6\%) to control the extent of infection. Most patients spent a total of 35 days on the surgical floor on average, ranging from 7 - 60 days, notably spending a mean of 4 days in the Intensive Care Unit (range 2-17days). The mortality rate was calculated to be $24 \%$ (17 out of 72 patients included in the study). Most of these patients were found to be in shock on initial evaluation and a high white cell count $(>25,000 \times$ $\left.10^{3} / \mu \mathrm{L}\right)$, raised serum creatinine $(>2 \mathrm{mg} / \mathrm{dL})$ and/or heart disease. Nine out of 23 patients meeting these criteria died (39\%). Mortality was $16.32 \%$ in patients who were not received in shock $(8 / 49$ patients). Details are shown in Table-4. 
Culture swabs were taken from each patient included in the study, 61 out of 72 patients had at least one pathogen positive in the reports $(85 \%)$. Multiple microbes were documented in 28 patients $(39 \%)$ and 11 patients received negative results. $(15 \%)$. S Pyogenes was the most common pathogen isolated from the cultures $(\mathrm{n}=23 ; 32 \%)$, either alone $(\mathrm{n}=16)$, or along with S. Aureus ( $\mathrm{n}=7) .39$ Patients (54\%) had Type I NSTI and $22(31 \%)$ had Type II NSTI. Bacteraemia was found in $38 \%$ of patients. Clostridial, MRSA, Acinobacter and Fungal infections were associated with the highest mortality.

\section{DISCUSSION}

Diabetes mellitus, immunocompromising conditions, immune-suppressive therapies, vascular disease, and obesity are common comorbidities in patients with NSTIs which have been pointed out by many authors and our experience showed similar results as there was evidence of immunosuppressive treatment in $31.94 \%$ and immunosuppressive disease in $48.61 \%$ of our patients. ${ }^{1-7}$ Such patients usually present with signs and symptoms of sepsis and reduced survival is noted specially in patients who do not receive prompt surgical treatment under broad spectrum antibiotic cover and accelerated resuscitation. ${ }^{8,13}$

However, it is interesting to note that $33 \%$ of our patients had absolutely no comorbidities. Although increasing comorbidity index is associated with increased mortality by most authors ${ }^{1-7}$, even in these patients with no comorbidities, delayed diagnosis and surgical treatment leads to significant morbidity and mortality and thus adverse outcomes ${ }^{9,13}$. Thus, a high index of suspicion even in these previously fit patients cannot be over emphasized for a favourable outcome. ${ }^{9,10}$

Undoubtedly, NSTIs are best treated in large tertiary care centers where all intensive care/ multidisciplinary facilities and experience is available. The effect of transfer to such centers and the resulting delay in treatment has been studied by other authors who have found that transfer status is associated with a higher mortality rate in NSTIs. ${ }^{11,13}$ We share a similar observation although our data on this aspect is compromised. We feel that a prospective study is warranted to illuminate further what factors contribute to the higher mortality rate in these very ill patients.

Although injection sites (IM/SC/IV) were the commonest infectious entry pathways $(46 \%)$ in our series, $8 \%$ of the necrotizing infections were found to be in post-operative surgical wounds and were associated with a very high mortality (4 out of 6 patients, mortality $67 \%$ ). NSTIs complicating surgical wounds have been reported by various authors, are difficult to recognize and manage and associated with a significant morbidity and mortality. ${ }^{12,14}$ The 4 patients with necrotizing postoperative infections in our series who died suffered from delay in diagnosis and/or transfer delays leading to a delay in surgical intervention and thus a poor outcome. Three of these patients had been referred from other hospitals and were too unstable for prompt surgical debridement and had to be resuscitated for more than 12 hours before they could be shifted to the operation theatre. Two of these had clostridial infections (Fig-2 \& 3).

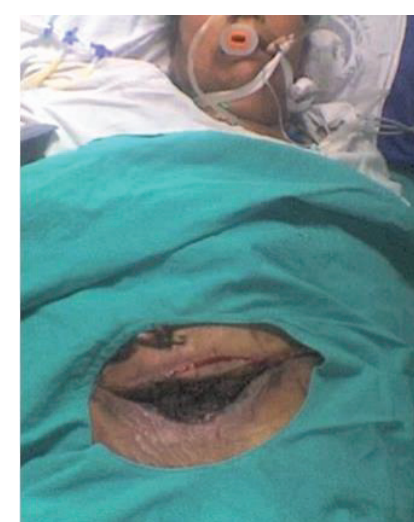

Fig-2: Clostridal NSTIs after an open cholecystectomy in diabetic patient.

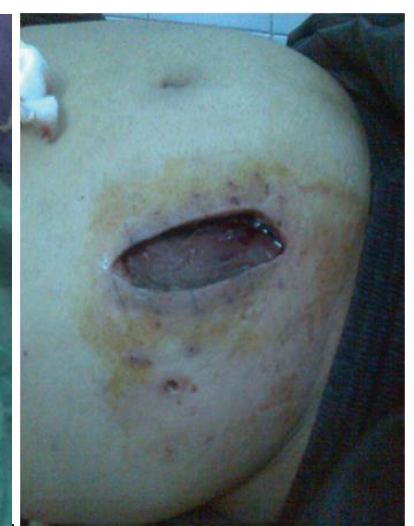

Fig-3: 5 days after appendectomy patient is Sepsis. Wound opened to reveal extensive necrotizing Myositis (Clostridial) with near normal overlying skin
One of the four patients with post-operative NSTIs who died included one of our own patients who had undergone an open necrosectomy for infected pancreatic necrosis and in whom the Fungal Necrotizing Surgical Site Infection was recognized too late (Fig-4). This was the case in three other patients among those with compromised immunity and with Fungal NSTIs proven at some stage. Fungal NSTIs are more frequent in patients on immunosuppressive treatments and are associated with significant in-hospital mortality. ${ }^{15}$ However, early recognition of the problem in a patient unresponsive to repeated serial debridement and broad-spectrum antibiotic cover, empiric treatment with antifungals should be given, particularly in those patients who are on immunosuppressive therapy, as it has shown to decrease mortality in admitted patients with fungal NSTIs. ${ }^{15,16,17}$ 


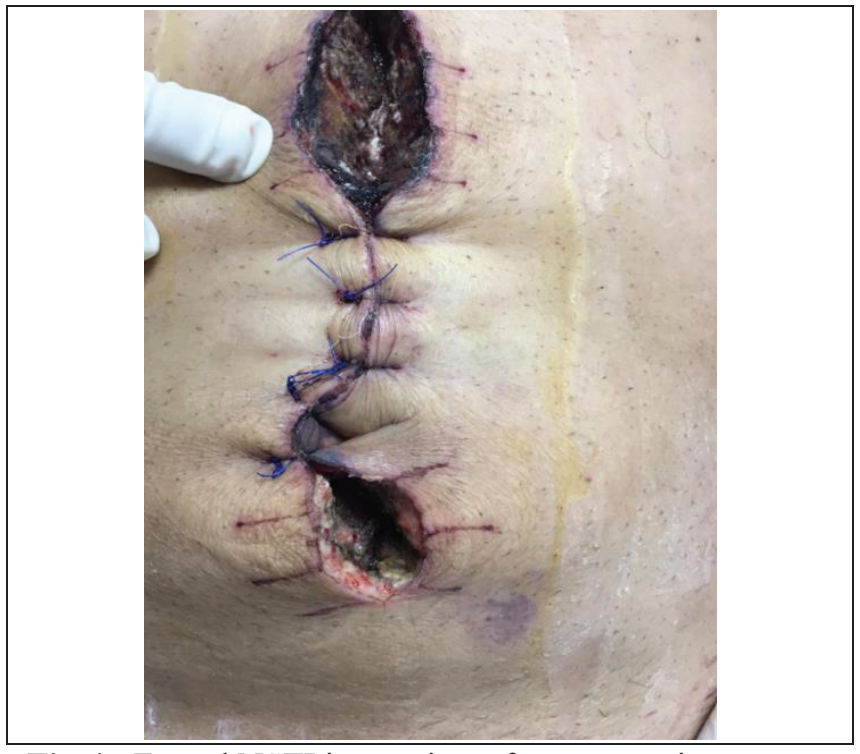

Fig-4: Fungal NSTI in a patient after pancreatic Necrosectomy.

A recent landmark systematic review and metaanalysis by Nawijn et al showed that although average mortality rates reported for NSTIs have remained constant (around 20\%) over the past 2 decades or more, surgical debridement to fresh healthy bleeding margins at the earliest possible time after admission lowers the mortality rate for NSTI by almost $50 \%$. Early surgical debridement of NSTIs within 12 hours is essential for reducing the mortality rate, while surgical intervention within 6 hours even further improve outcomes. ${ }^{13}$ Like most other authors, we share similar findings. Our records showed that $23.5 \%$ of the total mortalities were operated before 12 hours while $76.5 \%$ of the total mortalities were operated after 12 hours or beyond. Therefore, timing of the first surgery is of the essence and there indeed does exist a "Golden Hour" for the Management of NSTIs. ${ }^{11,13}$ Like most other authors our data also shows a mean of 5 debridements for the survivors thus highlighting the importance of timely repeat serial debridements to arrest the spread of the NSTIs and to ensure improved survival. ${ }^{1-17}$

Twenty three $(32 \%)$ patients in our series were received in shock with raised white cell counts and evidence of impaired renal function. The mortality among these patients was 39\% (9/23 patients) compared to $16.32 \%$ mortality in patients who were not received in shock ( $8 / 49$ patients). So, it is obvious that the mortality was almost doubled in patients who had shock and evidence of organ dysfunction at the time of admission. Although our data is lacking, it has been observed that a combination of multi organ dysfunction and comorbidities like heart disease, diabetes, obesity, immune compromise and NSTI trunkal involvement. (Fig-5A \& 5B) either primarily or secondarily led to mortalities even in patients who were not received in shock. These are the findings of most other authors who have written about the subject ${ }^{1-5,7-9,11,13,19}$. Delayed or suboptimal primary or subsequent serial debridements ${ }^{13}$ and the presence of Clostridial, ${ }^{20}$ Acinobacter, ${ }^{21,22}$ MRSA or Fungi ${ }^{15,16,17}$ as the infecting organisms was related to a higher mortality. Overwhelming sepsis was the cause of death in most of our patients except two who died due to major cardiac events during recovery in the hospital.

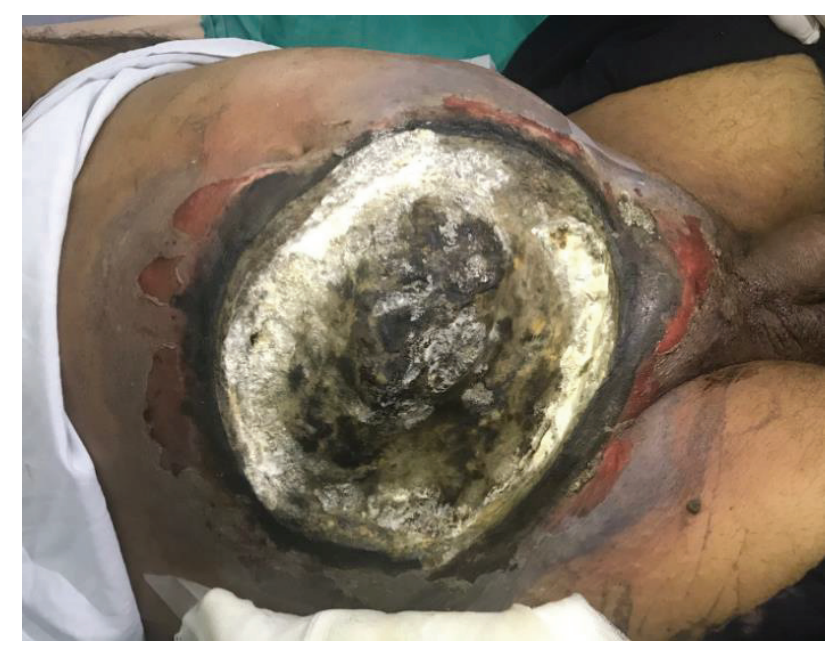

Fig-5A: NSTI of the torso with superimposed fungal infection secondary to SC Insulin injections in a diabetic. Notice the blue areas of extension after the third debridement.

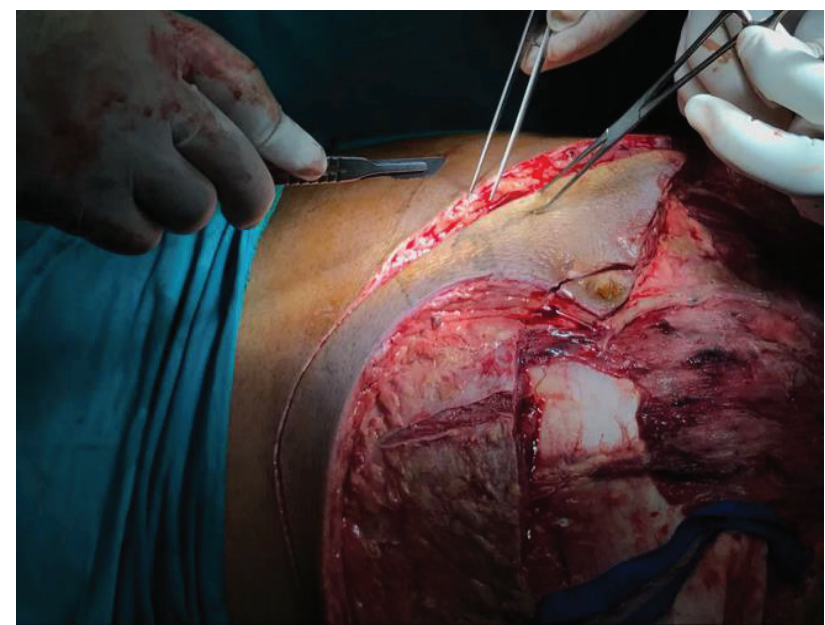

Fig-5B: Same patient as in Fig-5A. Sharp excision to fresh healthy bleeding tissues.

Severe NSTIs of the perineum extending onto the limbs and trunk as the patient shown in Fig-6A may require faecal diversion in addition to prompt serial debridements. Survivors will require the help of the plastic surgeons for early reconstruction as the wounds get better (Fig-6B). 


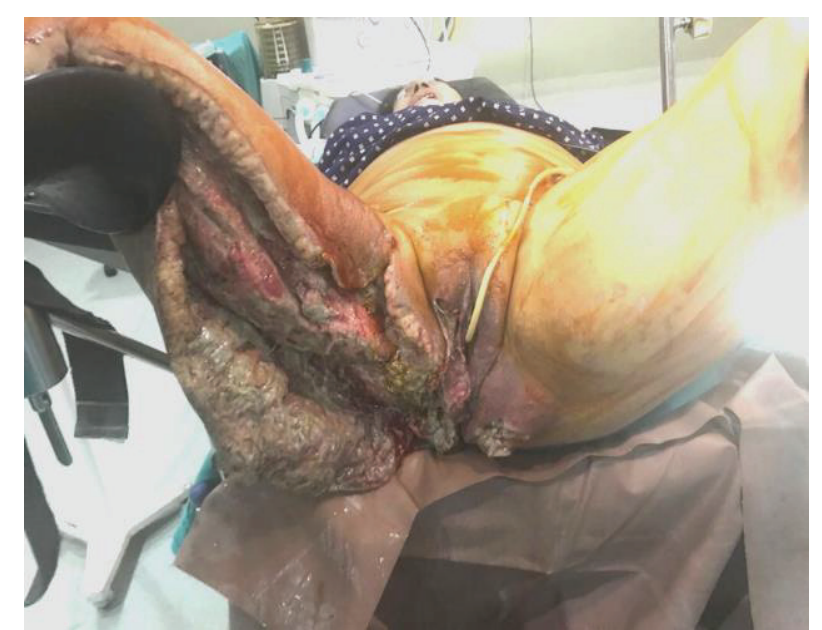

Fig-6A: Severe NSTI of the perineum involving a gas forming organism secondary to an IM NSAID injection in a diabetic extending onto the trunk and right thigh at the second debridement. Needed a diverting transverse loop colostomy.

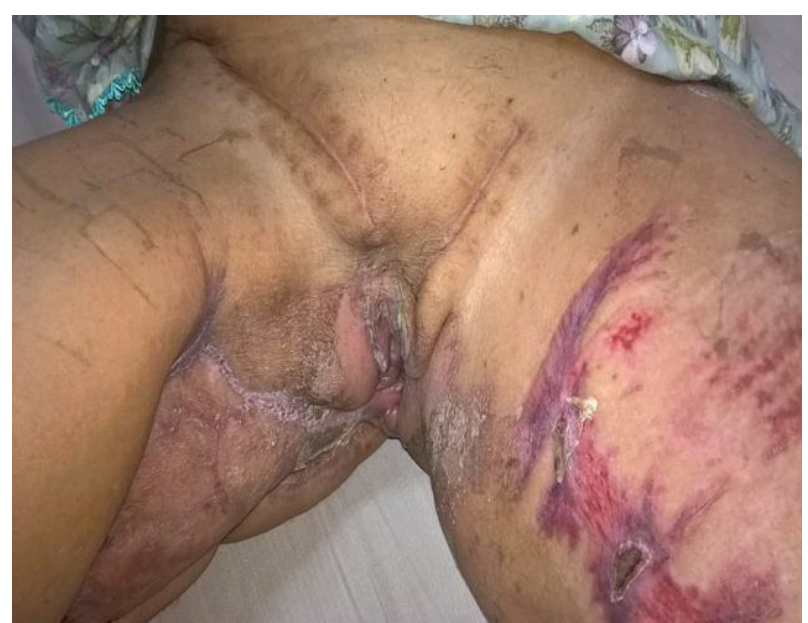

Fig-6B: The same patient as in Fig-6A after 2months and reconstruction. Colostomy was reverted after 5 months.

A study done at Aga Khan University Hospital Karachi showed that necrotizing infections of the head and neck region are fast spreading and are often not diagnosed properly. Aggressive strategies for treatment, both surgical and medical are required for proper management but late diagnosis and extension beyond the neck region into the chest carries poor prognosis. ${ }^{26} \mathrm{~A}$ case report published in 2020, where a patient with no co-morbids presented at Liaqat National Hospital, Karachi with an acute abdomen and was later diagnosed with retroperitoneal necrotizing fasciitis which is difficult to diagnose and the only option of treatment is prompt surgical intervention. ${ }^{27}$

Another Pakistani study suggested that in patients presenting with Necrotizing Fasciitis of the Lower Limb, sepsis was the commonest complication $(70 \%)$, while the most common cause of death in these patients was myocardial infarction and the mortality rate was reported to be around $30 \%$.
Diabetes mellitis was positive in the history of most patients. ${ }^{28}$ So a multidisciplinary approach in a tertiary care hospital is the best way to treat these patients.

\section{CONCLUSION}

Delay in diagnosis and surgical treatment, the presence of shock at admission accompanied by evidence of organ dysfunction, increasing comorbidity index and the presence of a nasty micro-organism (clostridia, fungi) all contribute to increased mortality in patients with NSTIs. Diagnosing these infections early, followed by prompt resuscitation, a broad spectrum antibiotic cover and extensive surgical debridement are the cornerstones in improving the outcome in these desperately ill patients. Increased time from admission to surgical management is associated with a higher mortality. Therefore, timing of the first surgery is of the essence thus highlighting the importance of the "Golden Hour" for the Management of NSTIs.

\section{REFERENCES}

1. Gupta Y, Chhetry M, Pathak KR, Jha RK, Ghimire N, Mishra BN, Karn NK, Singh GK, Bhagabati JN. Risk Factors For Necrotizing Fasciitis And Its Outcome At A Tertiary Care Centre. J Ayub Med Coll Abbottabad. 2016 Oct-Dec; 28(4):680-682. PMID: 28586594.

2. Bonne SL, Kadri SS. Evaluation and Management of Necrotizing Soft Tissue Infections. Infect Dis Clin North Am. 2017 Sep;31(3):497-511.

3. Van Sambeek CHL, van Stigt SF, Brouwers L, Bemelman M. Necrotising fasciitis: a ticking time bomb? BMJ Case Rep. 2017 Oct 4; 2017:bcr2017221770.

4. Hua C, Bosc R, Sbidian E, De Prost N, Hughes C, Jabre P, Chosidow O, Le Cleach L. Interventions for necrotizing soft tissue infections in adults. Cochrane Database Syst Rev. 2018 May 31; 5(5):CD011680.

5. Yilmazlar T, Ozturk E, Alsoy A, Ozguc H. Necrotizing soft tissue infections: APACHE II score, dissemination, and survival. World J Surg. 2007 Sep; 31(9):1858-62.

6. Hefny AF, Eid HO, Al-Hussona M, Idris KM, AbuZidan FM. Necrotizing fasciitis: a challenging diagnosis. Eur J Emerg Med. 2007 Feb; 14(1):50-2.

7. Giuliano A, Lewis F Jr, Hadley K, Blaisdell FW. Bacteriology of necrotizing fasciitis. Am J Surg. 1977 Jul; 134(1):52-7.

8. Chen KJ, Klingel M, McLeod S, Mindra S, Ng VK. Presentation and outcomes of necrotizing soft tissue infections. Int J Gen Med. 2017 Jul 31; 10:215-220.

9. Hedetoft M, Madsen MB, Madsen LB, Hyldegaard O. Incidence, comorbidity and mortality in patients 
with necrotising soft-tissue infections, 2005-2018: a Danish nationwide register-based cohort study. BMJ Open. 2020 Oct 16; 10(10):e041302.

10. Ramakrishnan K, Salinas RC, Agudelo Higuita NI. Skin and Soft Tissue Infections. Am Fam Physician. 2015 Sep 15; 92(6):474-83.

11. Khoury MK, Pickett ML, Cripps MW, Park SY, Nagaraj MB, Hranjec T, Hennessy SA. Transfer Is Associated with a Higher Mortality Rate in Necrotizing Soft Tissue Infections. Surg Infect (Larchmt). 2020 Mar; 21(2):136-142.

12. Yiasemidou $M$, Majumder $S$, Basheer $M$. Necrotising fasciitis after laparoscopic rectal cancer surgery. Ann R Coll Surg Engl. 2017 Apr; 99(4):e113-e114.

13. Nawijn F, Smeeing DPJ, Houwert RM, Leenen LPH, Hietbrink F. Time is of the essence when treating necrotizing soft tissue infections: a systematic review and meta-analysis. World J Emerg Surg. 2020 Jan 8; $15: 4$.

14. Urschel JD. Necrotizing soft tissue infections. Postgrad Med J. 1999 Nov; 75(889):645-9.

15. Khoury MK, Heid CA, Cripps MW, Pickett ML, Nagaraj MB, Johns M, Lee F, Hennessy SA. Antifungal Therapy in Fungal Necrotizing Soft Tissue Infections. J Surg Res. 2020Dec; 256:187-192

16. Horn CB, Wesp BM, Fiore NB, Rasane RK, Torres M, Turnbull IR, Ilahi ON, Punch LJ, Bochicchio GV. Fungal Infections Increase the Mortality Rate ThreeFold in Necrotizing Soft-Tissue Infections. Surg Infect (Larchmt). 2017 Oct; 18(7):793-798.

17. Brook I. Microbiology and management of soft tissue and muscle infections. Int J Surg. 2008 Aug; 6(4):328-38.

18. Meleney FL. Bacterial Synergism in Disease Processes: With a Confirmation of the Synergistic Bacterial Etiology of a Certain Type of Progressive Gangrene of the Abdominal Wall. Ann Surg. 1931 Dec; 94(6):961-81.

19. Bruun T, Rath E, Madsen MB, Oppegaard O, Nekludov M, Arnell P, Karlsson Y, Babbar A, Bergey F, Itzek A, Hyldegaard O, Norrby-Teglund A, Skrede S; INFECT Study Group. Risk Factors and Predictors of Mortality in Streptococcal Necrotizing Soft-tissue Infections: A Multicenter Prospective Study. Clin Infect Dis. 2021 Jan 27; 72(2):293-300.

20. Leiblein M, Wagner N, Adam EH, Frank J, Marzi I, Nau C. Clostridial Gas Gangrene - A Rare but Deadly Infection: Case series and Comparison to Other Necrotizing Soft Tissue Infections. Orthop Surg. 2020 Dec; 12(6):1733-1747.

21. Guerrero DM, Perez F, Conger NG, Solomkin JS, Adams MD, Rather PN, Bonomo RA. Acinetobacter baumannii-associated skin and soft tissue infections: recognizing a broadening spectrum of disease. Surg Infect (Larchmt). 2010 Feb; 11(1):49-57.

22. Ali A, Botha J, Tiruvoipati R. Fatal skin and soft tissue infection of multidrug resistant Acinetobacter baumannii: A case report. Int J Surg Case Rep. 2014; 5(8):532-6.

23. Berbudi A, Rahmadika N, Tjahjadi AI, Ruslami R. Type 2 Diabetes and its Impact on the Immune System. Curr Diabetes Rev. 2020; 16(5):442-449.

24. Cancer-Induced Immunosuppression: IL-18-Elicited Immunoablative NK Cells Magali Terme, Evelyn Ullrich, Laetitia Aymeric, Kathrin Meinhardt, Jérôme D. Coudert, Mélanie Desbois, François Ghiringhelli, Sophie Viaud, Bernard Ryffel, Hideo Yagita, Lieping Chen, Salaheddine Mécheri, Gilles Kaplanski, Armelle Prévost-Blondel, Masashi Kato, Joachim L. Schultze, Eric Tartour, Guido Kroemer, Mariapia Degli-Esposti, Nathalie Chaput and Laurence Zitvogel Cancer Res June 1 2012; (72) (11) 2757-2767.

25. Noor MT, Manoria P. Immune Dysfunction in Cirrhosis. J Clin Transl Hepatol. 2017; 5(1):50-58.

26. Ikram M, Saeed O, Ali SS, Salahuddin I. Necrotizing fasciitis of head \& neck: the Pakistani experience. Asian J Surg. 2002 Jan; 25(1):13-7.

27. 1. Beg A, Qureshi O, Siddiqui F, Khurshaidi N. Retroperitoneal necrotizing fasciitis in a 42-year-old male patient: A case report [Internet]. 2020 [cited 3 May 2021]. Available from: http://doi.org/10.47391/JPMA.647

28. Malik ZI. Necrotizing Fasciitis of Lower Limb: A Surgical Emergency. JRMC.; 16(2):135-7.

\section{The Authors:}

Prof. Haroon Javaid Majid

Head, Dept. of General Surgery \& Surgical Oncology, Shaikh Zayed Medical Complex, Lahore.

Prof. Muhammad Imran Anwar

Head, Department of Surgery (Unit-II),

Shaikh Zayed Medical Complex, Lahore.

Dr. Muhammad Zaeem Khalid

Trainee Registrar,

Department of Surgery (Unit-I),

Shaikh Zayed Medical Complex, Lahore.

Dr. Shafique-Ur-Rehman

Senior Registrar,

Department of Surgery (Unit-I),

Shaikh Zayed Medical Complex, Lahore.

Dr. Muhammad Amir Jameel

Senior Registrar,

Department of Surgery (Unit-II),

Shaikh Zayed Medical Complex, Lahore.

\section{Corresponding Author:}

Prof. Haroon Javaid Majid

Head, Dept. of General Surgery \& Surgical Oncology, Shaikh Zayed Medical Complex, Lahore.

E-mail: hjmajid@gmail.com 